\title{
G Research Square \\ Baseline Interleukin-6 Level Predicts Risk of Severe COVID-19: A Two-Center, Retrospective Study
}

\section{Weigang Zhu}

The Fourth Affiliated Hospital, School of Medicine, Zhejiang University

\section{Yingping Wu}

The Fourth Affiliated Hospital, School of Medicine, Zhejiang University

\section{Yueping Liu}

General Hospital of the Central Theater Command

\section{Bin Li}

The Fourth Affiliated Hospital, School of Medicine, Zhejiang University

\section{Pian Xiong}

The Fourth Affiliated Hospital, School of Medicine, Zhejiang University

\section{Dawei Cui}

The First Affiliated Hospital, Zhejiang University School of Medicine https://orcid.org/0000-0003-38401486

\section{Bo Diao}

General Hospital of Central Theater Command

Jianguo Wu ( $\nabla$ wujianguo@zju.edu.cn )

The Fourth Affiliated Hospital, School of Medicine, Zhejiang University

\section{Research article}

Keywords: SARS-CoV-2, COVID-19, Interleukin-6, Predictive factor

Posted Date: November 11th, 2020

DOI: https://doi.org/10.21203/rs.3.rs-68501/v1

License: (c) (1) This work is licensed under a Creative Commons Attribution 4.0 International License.

Read Full License 


\section{Abstract}

Background:The severe acute respiratory syndrome coronavirus-2 (SARS-CoV-2) pandemic has affected almost every country. Interleukin-6 (IL-6), a cytokine secreted by CD4+ T cell, has been shown to be a reliable marker of disease severity and a useful parameter for monitoring progression of coronavirus disease-2019 (COVID-19). However its value as a predictor of severe disease has not been assessed.

Methods:A total of 160 laboratory-confirmed COVID-19 patients admitted to two hospitals were enrolledand separated into two groups according to whether or not they progressed to develop severe illness. Demographic and clinical characteristics at admission were compared between the groups.

Results: Patients who developed severe COVID-19 had significantly higher baseline IL-6 levels than patients who had mild disease course in hospital $(P<0.001)$. Patients were further grouped according to quartiles of IL-6 level. The cumulative incidence of severe illnesswas significantly higher in the third and fourth quartiles groups than in the first quartile group ( $55 \%$ vs. $15 \%$ and $80 \%$ vs. $15 \%$, respectively;both $P<$ 0.001). In multivariate logistic regression analysis, the risk for developing severe disease was markedly higher in the highest IL-6 quartile than in the lowest quartile (odds ratio: 14.95; 95\% confidence interval: 3.65-61.30; $P<0.001)$. Receiver operating characteristic curve analysis of potential predictive variables showed the area under the curve to be largest for baseline IL-6, with the value of $5.20 \mathrm{pg} / \mathrm{mL}$ having the best balance of sensitivity and specificity for predicting risk of severe COVID-19.

Conclusion: Serum baseline IL-6 appears to be a reliable predictor of risk of severe COVID-19. Early intervention may be advisable in patients with serum IL-6 levels $>5.20 \mathrm{pg} / \mathrm{mL}$, even if initial symptoms are mild.

\section{Background}

In the eight months since the severe acute respiratory syndrome coronavirus-2 (SARS-CoV-2) was identified as the pathogen of anovel pneumonia in Wuhan, China, the organism has spread rapidly across the world [1, 2]. As of 9 August 2020, a total of 19,462,112 COVID-19 cases have beenconfirmed worldwide, and 722,285 patients havedied. Disease severity varies widely, with mortality being much higher in patients with severe COVID-19 than in those with mild illness[3]. Amethod for rapid triage of patients is therefore urgently needed. Interleukin-6 (IL-6), a cytokine secreted by CD $4+T$ cell,has been shown to be a reliable marker ofdisease severity and a useful parameter for monitoring COVID-19 progression [4-6], but its value for predicting risk of severe illness has not been examined. The objective of this retrospective study was to determinewhether serum IL-6 level at admission can serve as a predictor of risk for severe COVID-19 in hospitalized patients.

\section{Result}

\section{Demographic and clinical characteristics}


A total of 160 patients ( $58.8 \%$ males) from two hospitals were included in this study. The median age was 53.8 years. Comorbidities were present in 59/160 (36.9\%) patients and included hypertension (37, $23.1 \%)$, cardio-cerebrovascular disease $(26,16.3 \%)$, diabetes mellitus $(15,9.4 \%)$, chronic pulmonary disease $(9,5.6 \%)$, chronic renal disease $(4,2.5 \%)$, and cancer $(5,3.1 \%)$. Computed tomography (CT) scans revealed multilobar pulmonary infiltrates in 128/160 (80.0\%) patients (Table 1). Neutrophil count, neutrophil-to-lymphocyte ratio (NLR), neutrophil-to-CD8 + T cell ratio (N8R), and serum IL-6 and lactate dehydrogenase (LDH) levels were significantly higher in the SC group than in the MS group, while lymphocyte count, CD4 + T cell count, CD8 + T cell count, B cell count, and NK cell count were significantly lower (all $P<0.05$; Table 1). 
Table 1

Demographic and clinical characteristics of COVID-19 patients at admission

\begin{tabular}{|c|c|c|c|c|}
\hline & $\begin{array}{l}\text { All patients } \\
(\mathrm{N}=160)\end{array}$ & $\begin{array}{l}\text { MS } \\
(n=88)\end{array}$ & $\begin{array}{l}\text { SC } \\
(n=72)\end{array}$ & $P$ \\
\hline Age, $y$, mean $\pm S D$ & $53.8 \pm 17.8$ & $51.5 \pm 16.5$ & $56.5 \pm 19.0$ & 0.076 \\
\hline Sex, n (\%) & & & & 0.923 \\
\hline Male & $94(58.8)$ & $52(59.1)$ & $42(58.3)$ & \\
\hline Female & $66(41.2)$ & $36(40.9)$ & $30(41.7)$ & \\
\hline \multicolumn{5}{|l|}{ Underlying disease, $\mathrm{n}(\%)$} \\
\hline Hypertension & $37(23.1)$ & $18(20.5)$ & $19(26.4)$ & 0.376 \\
\hline $\begin{array}{l}\text { Cardio-cerebrovascular } \\
\text { disease }\end{array}$ & $26(16.3)$ & $8(9.1)$ & $18(25.0)$ & 0.007 \\
\hline Diabetes & $15(9.4)$ & $7(8.0)$ & $8(11.1)$ & 0.496 \\
\hline Chronic pulmonary disease & $9(5.6)$ & $2(2.3)$ & $7(9.7)$ & 0.091 \\
\hline Chronic renal disease & $4(2.5)$ & $0(0.0)$ & $4(5.6)$ & 0.084 \\
\hline Cancer & $5(3.1)$ & $3(3.4)$ & $2(2.8)$ & 1.000 \\
\hline Radiographic findings, $\mathrm{n}(\%)$ & & & & $<.001$ \\
\hline Negative & $12(7.5)$ & $12(13.6)$ & $0(0.0)$ & \\
\hline Unilobar lesion & $20(12.5)$ & $16(18.2)$ & $4(5.6)$ & \\
\hline Multilobar lesion & $128(80.0)$ & $60(68.2)$ & $68(94.4)$ & \\
\hline \multicolumn{5}{|l|}{$\begin{array}{l}\text { Laboratory results, median } \\
\text { (IQR) }\end{array}$} \\
\hline Neutrophil count $\left(\times 10^{9} / \mathrm{L}\right)$ & $3.24(2.36-4.68)$ & $\begin{array}{l}2.96(2.24- \\
4.24)\end{array}$ & $3.70(2.49-5.72)$ & 0.024 \\
\hline Lymphocyte count $\left(\times 10^{9} / \mathrm{L}\right)$ & $1.24(0.84-1.70)$ & $\begin{array}{l}1.52(1.07- \\
1.92)\end{array}$ & $0.97(0.58-1.38)$ & $\dot{0.001}$ \\
\hline NLR & $2.56(1.69-4.32)$ & $\begin{array}{l}1.92(1.56- \\
3.07)\end{array}$ & $3.54(2.32-8.90)$ & $\dot{0} 001$ \\
\hline CD4 $+\mathrm{T}$ cell count $\left(\times 10^{6} / \mathrm{L}\right)$ & $412(251-706)$ & $581(372-810)$ & $281(168-484)$ & $\dot{0} 001$ \\
\hline
\end{tabular}

MS, mild steady group; SC, severe change group; SD, standard deviation; NLR, neutrophil-tolymphocyte ratio; N8R, neutrophil-to-CD8 + T cell ratio; IQR, interquartile range 


\begin{tabular}{|c|c|c|c|c|}
\hline & $\begin{array}{l}\text { All patients } \\
(\mathrm{N}=160)\end{array}$ & $\begin{array}{l}\text { MS } \\
(n=88)\end{array}$ & $\begin{array}{l}\text { SC } \\
(n=72)\end{array}$ & $P$ \\
\hline $\mathrm{CD} 8+\mathrm{T}$ cell count $\left(\times 10^{6} / \mathrm{L}\right)$ & $263(149-400)$ & $320(217-479)$ & $201(98-294)$ & $\begin{array}{l}<.001 \\
0.001\end{array}$ \\
\hline N8R & $\begin{array}{l}12.35(6.59- \\
25.80)\end{array}$ & $\begin{array}{l}8.25(6.24- \\
18.71)\end{array}$ & $\begin{array}{l}18.53(9.22- \\
48.47)\end{array}$ & $\begin{array}{l}< \\
0.001\end{array}$ \\
\hline B cell count $\left(\times 10^{6} / \mathrm{L}\right)$ & $152(88-254)$ & $198(130-292)$ & $119(74-168)$ & $\begin{array}{l}< \\
0.001\end{array}$ \\
\hline NK cell count $\left(\times 10^{6} / \mathrm{L}\right)$ & $166(101-274)$ & $183(118-301)$ & $147(71-249)$ & 0.024 \\
\hline IL-6 (pg/mL) & $9.4(3.03-27.6)$ & $3.6(2.2-13.8)$ & $22.3(9.4-43.6)$ & $\begin{array}{l}< \\
0.001\end{array}$ \\
\hline $\begin{array}{l}\text { Alanine aminotransferase } \\
(\mathrm{U} / \mathrm{L})\end{array}$ & $22(16-33)$ & $21(15-33)$ & $23(18-33)$ & 0.450 \\
\hline Lactate dehydrogenase (U/L) & $205(170-268)$ & $193(160-227)$ & $240(190-316)$ & $\begin{array}{l}< \\
0.001\end{array}$ \\
\hline Creatine kinase $(\mathrm{U} / \mathrm{L})$ & $110(76-180)$ & $111(76-157)$ & $108(75-212)$ & 0.518 \\
\hline $\begin{array}{l}\text { Blood urea nitrogen } \\
(\mathrm{mmol} / \mathrm{L})\end{array}$ & $4.27(3.43-5.31)$ & $\begin{array}{l}4.18(3.44- \\
4.83)\end{array}$ & $4.47(3.43-6.18)$ & 0.178 \\
\hline Serum creatinine $(\mu \mathrm{mol} / \mathrm{L})$ & $65(54-78)$ & $66(55-78)$ & $64(54-78)$ & 0.689 \\
\hline
\end{tabular}

\section{Correlations between baseline IL- 6 and other parameters}

Figure 1 shows the correlations between baseline IL- 6 and various parameters. IL- 6 level was positively correlated with NLR $(r=0.378, P<0.001)$, N8R $(r=0.334, P<0.001)$, LDH level $(r=0.498, P<0.001)$, and creatine kinaselevel $(r=0.206, P=0.009)$, but negatively correlated with lymphocyte count $(r=-0.422, P<$ $0.001), \mathrm{CD} 4+\mathrm{T}$ cell count $(r=-0.440, P<0.001), \mathrm{CD} 8+\mathrm{T}$ cell count $(r=-0.356, P<0.001)$, and B cell count $(r=-0.383, P<0.001)$.

\section{Association between baseline IL-6 and risk of severe COVID-19}

After the patients were separatedinto IL-6 quartile subgroups, the incidenceof severe illness was found to increase with increase in IL-6 level. The cumulative incidence was significantly higher in the third and fourth quartile subgroups than in the first quartile subgroup (55\% vs. $15 \%$ and $80 \%$ vs. $15 \%$, respectively; both $P<0.001$; Fig. $2 A$ ). Duration of hospitalization was also significantly longer in the higher quartile patient groups (all $P<0.01$; Fig. 2B). The comorbidity-adjusted odds for severe illness increased significantly with increase inlL-6 level (Table 2; Model 1The trend did not change even after adjustment 
for age, sex, and comorbidityin multivariate logistic regression (Model 2) or after further adjustment for leukocyte subgroups (Model 3).

Table 2

Risk for severe COVID-19 in patients grouped according to quartiles of baseline IL-6

\begin{tabular}{|c|c|c|c|c|c|c|c|c|}
\hline $\begin{array}{l}\text { IL-6 } \\
(\mathrm{pg} / \mathrm{mL})\end{array}$ & $\begin{array}{l}\text { Number } \\
\text { of } \\
\text { patients }\end{array}$ & $\begin{array}{l}\text { Number } \\
\text { of } \\
\text { severe } \\
\text { events }\end{array}$ & $\begin{array}{l}\text { Model 1: } \\
\text { OR (95\% } \\
\text { Cl) }\end{array}$ & $\begin{array}{l}P \text { for } \\
\text { trend }\end{array}$ & $\begin{array}{l}\text { Model 2: } \\
\text { OR (95\% } \\
\text { Cl) }\end{array}$ & $\begin{array}{l}P \text { for } \\
\text { trend }\end{array}$ & $\begin{array}{l}\text { Model 3: } \\
\text { OR (95\% } \\
\text { Cl) }\end{array}$ & $\begin{array}{l}P \text { for } \\
\text { trend }\end{array}$ \\
\hline$<3.1$ & 40 & 6 & 1 & & 1 & & 1 & \\
\hline $3.1-9.4$ & 40 & 12 & $\begin{array}{l}2.84(0.91- \\
8.87)\end{array}$ & & $\begin{array}{l}3.04 \\
(0.95- \\
9.71)\end{array}$ & & $\begin{array}{l}3.89 \\
(0.97- \\
15.53)\end{array}$ & \\
\hline $\begin{array}{l}9.5- \\
27.6\end{array}$ & 40 & 22 & $\begin{array}{l}8.06(2.60- \\
24.98)\end{array}$ & & $\begin{array}{l}9.33 \\
(2.89- \\
30.10)\end{array}$ & & $\begin{array}{l}6.22 \\
(1.60- \\
24.15)\end{array}$ & \\
\hline$>27.6$ & 40 & 32 & $\begin{array}{l}24.81 \\
(7.29- \\
84.41)\end{array}$ & $\begin{array}{l}<.001 \\
0.00\end{array}$ & $\begin{array}{l}26.62 \\
(7.52- \\
94.25)\end{array}$ & $\begin{array}{l}<.001 \\
0.001\end{array}$ & $\begin{array}{l}14.95 \\
(3.65- \\
61.30)\end{array}$ & $\begin{array}{l}<.001 \\
0.001\end{array}$ \\
\hline
\end{tabular}

OR, odds ratio; $\mathrm{Cl}$, confidence interval; IL-6, interleukin-6.

Model 1: Adjustment made for comorbidities; Model 2: Adjustment made age, sex, and comorbidities; Model 3: Adjustment made for age, sex, comorbidities, neutrophil count, lymphocyte count, CD 4 + T cell count, CD $8+T$ cell count, B cell count, and NK cell count.

\section{Comparison of predictive values of different variables}

Baseline IL- 6 level, neutrophil count, NLR, and N8R were assessed for ability to predict risk of severe disease. In ROC analysis,the AUC for IL-6 $(0.798,95 \%$ Cl: $0.727-0.857)$ was significantly larger than the AUC for neutrophil count $(0.604,95 \% \mathrm{Cl}$ : $0.523-0.680)$ and N8R $(0.688,95 \% \mathrm{Cl}: 0.610-0.759)$. The AUC for IL-6 was not significantly different from the AUC of NLR $(0.720,95 \% \mathrm{Cl}: 0.644-0.788)$. The optimal cutoff values of the different variables were as follows:IL-6, $5.20 \mathrm{pg} / \mathrm{mL}$ (sensitivity: $91.67 \%$, specificity: 59.09\%), neutrophil count, $4.67 \times 10^{9} / \mathrm{L}$ (sensitivity: $36.11 \%$, specificity: $84.09 \%$ ), NLR,2.74 (sensitivity: 66.67\%, specificity: 72.73\%), and N8R,25.42 (sensitivity: 43.06\%, specificity: 89.77\%) (Table 3). 
Table 3

Optimal cutoff values of potential predictors of severe COVID-19 and their sensitivity and specificity

\begin{tabular}{|c|c|c|c|c|}
\hline & IL-6 (pg/mL) & $\begin{array}{l}\text { Neutrophil count }(x \\
\left.10^{9} / \mathrm{L}\right)\end{array}$ & NLR & N8R \\
\hline Cutoff value & 5.20 & 4.67 & 2.74 & 25.42 \\
\hline Sensitivity (\%) & 91.67 & 36.11 & 66.67 & 43.06 \\
\hline Specificity (\%) & 59.09 & 84.09 & 72.73 & 89.77 \\
\hline \multirow{2}{*}{$\begin{array}{l}\text { Area under ROC } \\
\text { curve } \\
(95 \% \mathrm{Cl})\end{array}$} & 0.798 & $0.604^{\#}$ & 0.720 & $0.688^{\#}$ \\
\hline & $\begin{array}{l}(0.727- \\
0.857)\end{array}$ & $(0.523-0.680)$ & $\begin{array}{l}(0.644- \\
0.788)\end{array}$ & $\begin{array}{l}(0.610- \\
0.759)\end{array}$ \\
\hline \multicolumn{5}{|c|}{$\begin{array}{l}\text { ROC, receiver operating characteristic; } \mathrm{Cl} \text {, confidence interval; NLR, neutrophil-to-lymphocyte ratio; } \\
\text { N8R, neutrophil-to-CD8 + T cell ratio. }\end{array}$} \\
\hline \multicolumn{5}{|l|}{${ }^{\#} P<0.05$ vs. IL-6 } \\
\hline
\end{tabular}

\section{Discussion}

The COVID-19 pandemic poses a great challenge to human society. Although case mortality for COVID-19 is relatively low, it has so far caused far more deaths than severe acute respiratory syndrome (SARS) and Middle East respiratory syndrome (MERS) combined [7, 8]. Becausemortality is very high inpatients with severe COVID-19 [3], it is essential to find reliable early predictors ofrisk for severe illness.

Previous studies in patients with severe COVID-19 have shownchanges in immune-inflammation parameters, e.g., low counts of lymphocytes and its subgroups, high neutrophil counts, high NLR, and elevated serum IL-6 level [4, 6, 9-11]; these changes were attributed to the severe and aberrant host immune response [12]. In our study, we found similar changes in patients who developed severe disease versus those who had mild disease:lymphocytes and all its subsets were significantly lower in the SC group, while neutrophil, NLR, N8R, and IL-6 were significantly higher (all $P<0.05$ ). Reduction in T lymphocyte counts may due to the direct invasion by SARS-CoV-2, similar to the mechanism reported in MERS-CoV infection [13]. In addition, autoimmune antibodies triggered by the viruscould decrease production and differentiation of T lymphocytes and other lymphocytes viainhibition of growthand suppression of hematopoiesis[11, 14]. Elevation of neutrophil counts usually indicates an inflammatory response, while decrease in lymphocyte counts suggests damage to the immune system; therefore, as the results of our study suggest, high NLR and N8R can serve as diagnostic markers for severe COVID-19 [9] and also be useful predictors of severe illness.

Huang et al.were the first to suggest that a cytokine storm could be associated with severe disease [1]; this was confirmed by subsequent studies $[15,16]$. IL-6 is a multifunctional cytokine involved in cell signaling and regulation of immune cells, and usually shows more significant serum levels changes than 
other cytokinesin inflammatory disease $[17,18]$. IL-6 reflects the intensity of inflammatory response in the body. Liu et al. and Zhe et al. have demonstrated that IL-6 plays a pivotal role in the severity of COVID-19 and thereforehas value for monitoring the progress of severely ill patients $[4,5]$. In our study, we found the cumulative incidence of severe illnessto be related to the baseline IL-6 level. Patients in the higher IL-6 quartile groups were significantly more likely to develop severe illness (Fig. 2A) and to need longer hospitalization (Fig. 2B). Since the severity of the disease corresponded to the intensity of inflammation, former phenomena could be explained.

Comorbidities such as diabetes and cancer can affect baseline IL-6 level [19, 20]; we therefore used logistic regression models to adjust for the effect of potential confounders. However, the significant association between baseline IL- 6 level andrisk of severe illnesspersisted even after adjustment for all potential confounders (Models1-3; Table 2).

Neutrophil count, NLR, N8R, and IL-6 level have all been previously shown to be useful prognostic indicatorsin severe COVID-19 [4-6, 9]. We performed ROC analysis to identify the variable with the best predictive value. The AUC of IL-6 was significantly larger than those of neutrophil count and N8R. The AUC of IL- 6 was comparable to that of NLR, which is currently widely accepted as a predictor of outcome in patients with COVID-19. However, the sensitivity of IL-6 was much higher than that of NLR $(91.67 \%$ vs.66.67\%). For any predictive or screening index, sensitivity is more important than specificity, the higher the sensitivity, the fewer the false-negative results. Thus, in addition to being a useful parameter for monitoring progression of disease in patients with COVID-19, baseline IL-6 could be a powerful predictor of risk of severe disease.

This study had some limitations. First, this was a retrospective analysis of a small sample and some bias is inevitable. Second, because of inconsistencies in data recording between the two centers, some clinical parameters could not be included in the analysis.

\section{Conclusion}

Baseline IL-6 levelappears to be areliable predictor of the risk for developing severe COVID-19. In patients with mild COVID-19 features on admission but serum IL-6 level $>5.20 \mathrm{pg} / \mathrm{mL}$, early interventionmight helpprevent progression to severe disease.

\section{Methods}

\section{Data source and collection}

This retrospective observational study was jointly performed by the Fourth Affiliated Hospital, School of Medicine, Zhejiang University, and the General Hospital of the Central Theater Command, and was approved by the Ethics Committees of both institutions (No. K20200027 and No. [2020]017 - 1, respectively). 
A total of 160 patients hospitalized for treatment of COVID-19 between January 10, 2020,and March 9 , 2020, were included in this retrospective study. COVID-19 was diagnosed according to the Chinese National Health Committee guidelines (version 7) [21]. The patients were separated into two groups according to the course of the disease during hospital stay: the mild steady (MS) group ( $n=88)$, comprising patients who had mild symptoms on admission and continued to have mild disease until recovery, and the severe change (SC) group, comprising patients who developed severe illness during hospitalization ( $n=72)$. Severe illness was defined as COVID-19 with any of the following: 1 ) shortness of breath, with respiratory rate $\geq 30 / \mathrm{min} ; 2$ ) oxygen saturation by pulse oximeter $\leq 93 \%$ in resting state; 3 ) ratio of partial pressure of arterial oxygen $\left(\mathrm{PaO}_{2}\right)$ to fraction of inspired oxygen $\left(\mathrm{FiO}_{2}\right) \leq 300 \mathrm{~mm} \mathrm{Hg}$ $(1 \mathrm{~mm} \mathrm{Hg}=0.133 \mathrm{kPa}$ ); or 4 ) increase in lesion size by $\geq 50 \%$ over $24-48$ hourson lung imaging. Data on

demographic characteristics, comorbidities, radiographic findings, and laboratory tests on admission, and duration of hospitalization, were extracted from the electronic medical records and compared between the groups. All data were cross-checked for consistency and accuracy before analysis. For a closer exploration of the association between baseline IL- 6 and risk of severe illness, we also grouped patients by IL-6 quartiles.

\section{Statistical analysis}

Continuous variables were expressed as means( \pm standard deviation) or medians (and interquartile ranges), and compared using the Student's t-test orthe Mann-Whitney $U$ test. Categorical variables were expressed as counts and percentages and compared using thechi-square test or Fisher exact test. Correlations between IL- 6 and other variables were analyzed by Spearman correlation analysis. One-way analysis of variance (ANOVA) with Bonferroni correction was used to compare the duration of hospitalization between IL-6 quartilepatient subgroups. Multivariate logistic regression analysis was performed to assess the association between IL-6 level and risk of severe COVID-19. Odds ratios (OR) and $95 \%$ confidence intervals $(95 \% \mathrm{Cl})$ were calculated. To compare the predictive values of different laboratory parameters, receiver operating characteristic (ROC) curves were plotted, and the areas under the curves (AUC) were compared. The Youden index was used to find the optimal cutoff values of each parameter forpredicting future severe illness. Statistical analysis was performed using SPSS 20.0 (IBM Corp., Armonk, NY, USA).Statistical significance was at $P \leq 0.05$ for all tests.

\section{Abbreviations}

SARS-CoV-2: Severe acute respiratory syndrome coronavirus-2; COVID-19: Coronavirus disease-2019; IL-6: Interleukin-6; CT: Computed tomography; NLR: Neutrophil-to-lymphocyte ratio; N8R: Neutrophil-to-CD8+ T cell ratio; LDH: Lactate dehydrogenase; MERS: Middle East respiratory syndrome; MS: Mild steady; SC: Severe change; OR: Odds ratios; Cl: Confidence intervals; ROC: Receiver operating characteristic; AUC: Areas under the curves

\section{Declarations}


Acknowledgements

We thank all the medical staff of the two institutions for their hard work and great efforts during the outbreak of COVID-19.

\section{Authors' contributions}

WGZ, YPW and JGW designed the research. YPL, BL and PX collected the data. WGZ, YPW and DWC contributed to analysis and interpretation of the data. YPL, BD and JGW interpreted the results and wrote the manuscripts. All authors have read and approved the manuscript]

\section{Funding}

This study was supported by the Science and Technology Project of Jinhua (No.2020XG-37) and the Medical Science and Technology Project of Zhejiang Province (No.2020ZH022).

\section{Availability of data and materials}

The datasets analysed during the current study are available from thecorresponding author on reasonable request.

\section{Ethics approval and consent to participate}

All participants provided written informed consent for the use oftheir information. This $r$ study wasapproved by the Ethics Committees ofThe Fourth Affiliated Hospital, School of Medicine, Zhejiang University, and the General Hospital of the Central Theater Commandboth.

\section{Consent for publication}

Not applicable.

\section{Competing interests}

The authors declare no competing interest.

\section{Author details}

${ }^{1}$ Department of Clinical Laboratory, The Fourth Affiliated Hospital, School of Medicine, Zhejiang University,Yiwu, China. ${ }^{2}$ Department of Infectious Diseases, The Fourth Affiliated Hospital, School of Medicine, Zhejiang University, Yiwu, China.

${ }^{3}$ Department of Medical Laboratory Center, General Hospital of the Central Theater Command, Wuhan, China. ${ }^{4}$ Department of Blood Transfusion, The First Affiliated Hospital, School of Medicine, Zhejiang University, Hangzhou, China. 


\section{References}

1. Huang $C$, Wang $Y, L i$ X, et al. Clinical features of patients infected with 2019 novel coronavirus in Wuhan, China. Lancet. 2020;395(10223):497-506.

2. World Health Organization. Coronavirus Disease (COVID-2019) Situation Reports. 2020; https://www.who.int/emergencies/diseases/novel-coronavirus-2019.

3. Li X, Xu S, Yu M, et al. Risk factors for severity and mortality in adult COVID-19 inpatients in Wuhan. J Allergy ClinImmunol. 2020;146(1):110-8.

4. Liu T, Zhang J, Yang Y, et al. The role of interleukin- 6 in monitoring severe case of coronavirus disease 2019. EMBO Mol Med. 2020;12(7):e12421.

5. Zhu Z, Cai T, Fan L, et al. Clinical value of immune-inflammatory parameters to assess the severityof coronavirus disease 2019. Int J Infect Dis. 2020;95:332-9.

6. Liu F, Li L, Xu M, Wu J, Luo D, Zhu Y, et al. Prognostic Value of interleukin-6, C-reactive Protein, and Procalcitonin in Patients With COVID-19. J ClinVirol. 2020;127:104370.

7. Centers for Disease Control and Prevetion. Frequently asked questions about SARS. 2019-07-24; https://www.cdc.gov/sars/about/faq.html.

8. World Health Organization. Middle East respiratory syndrome coronavirus (MERS-CoV). 2019-11-30; https://www.who.int/emerg encie s/mers-cov/en.

9. Liu J, Li S, Liu J, et al. Longitudinal characteristics of lymphocyte responses and cytokine profiles in the peripheral blood of SARS-CoV-2 infected patients.EBioMedicine. 2020;55:102763.

10. Liu R, Wang Y, Li J, et al. Decreased TCell Populations Contribute to the Increased Severity of COVID19. ClinChimActa. 2020;508:110-4.

11. He R, Lu Z, Zhang L, et al. The clinical course and its correlated immune status in COVID19pneumonia. J ClinVirol. 2020;127:104361.

12. Zhou Y, Fu B, Zheng X, et al. Aberrant pathogenic GM-CSF + T cells and inflammatory CD14 + CD16 + monocytes in severe pulmonary syndrome patients of a new coronavirus. medRxiv. 2020. https://doi.org/10.1101/2020.02.12.945576.

13. Chu H, Zhou J, Wong BH-Y, et al. Middle East Respiratory Syndrome Coronavirus Efficiently InfectsHuman Primary T Lymphocytes and Activates the Extrinsic and Intrinsic Apoptosis Pathways. J InfectDis. 2020;213(26):904-14.

14. Yang M, Li CK, Li K, et al. Hematological Findings in SARS Patients and Possible Mechanisms (Review). Int J Mol Med. 2004;14(2):311-5.

15. Chen L, Liu HG, Liu W, et al. Analysis of clinical features of 29 patients with 2019 novel coronavirus pneumonia.ZhonghuaJie. He He Hu Xi ZaZhi. 2020;43(3):203-8.

16. Xu Z, Shi L, Wang Y, et al. Pathological findings of COVID-19 associated with acute respiratory distress syndrome. Lancet Respir Med. 2020;8(4):420-2. 
17. Taniguchi K, Karin M. IL-6 and related cytokines as the critical lynchpins between inflammation and cancer.SeminImmunol. 2014;26(1):54-74.

18. Tang $Y$, Liao $C, X u X$, et al. Th1/Th2 cytokine profiles in $\mathrm{G}+/ \mathrm{G}$ - bacteremia in pediatric hematology/oncology patients. Pediatr Blood Cancer. 2012;58(1):50-4.

19. Landers-Ramos RQ, Blumenthal JB, Prior SJ. Serum IL-6 and sIL-6R in type 2 diabetes contribute to impaired capillary-like network formation. J AppIPhysiol (1985). 2019;127 (2):385 - 92.

20. Stoll JR, Vaidya TS, Mori S, et al. Association of IL-6 and TNF-a with mortality in hospitalized cancer patients. J Am AcadDermatol. 2020. https://doi.org/10.1016/j.jaad.2020.03.010.

21. National Health and Health Commission of the people's Republic of China. Diagnosis and Treatment of Pneumonia of New Coronavirus Infection (Trial Version 7). 2020-03-03; http://www.nhc.gov.cn/yzygj/s7653p/202003/46c9294a7dfe4cef80dc7f5912eb1989.shtml.

\section{Figures}



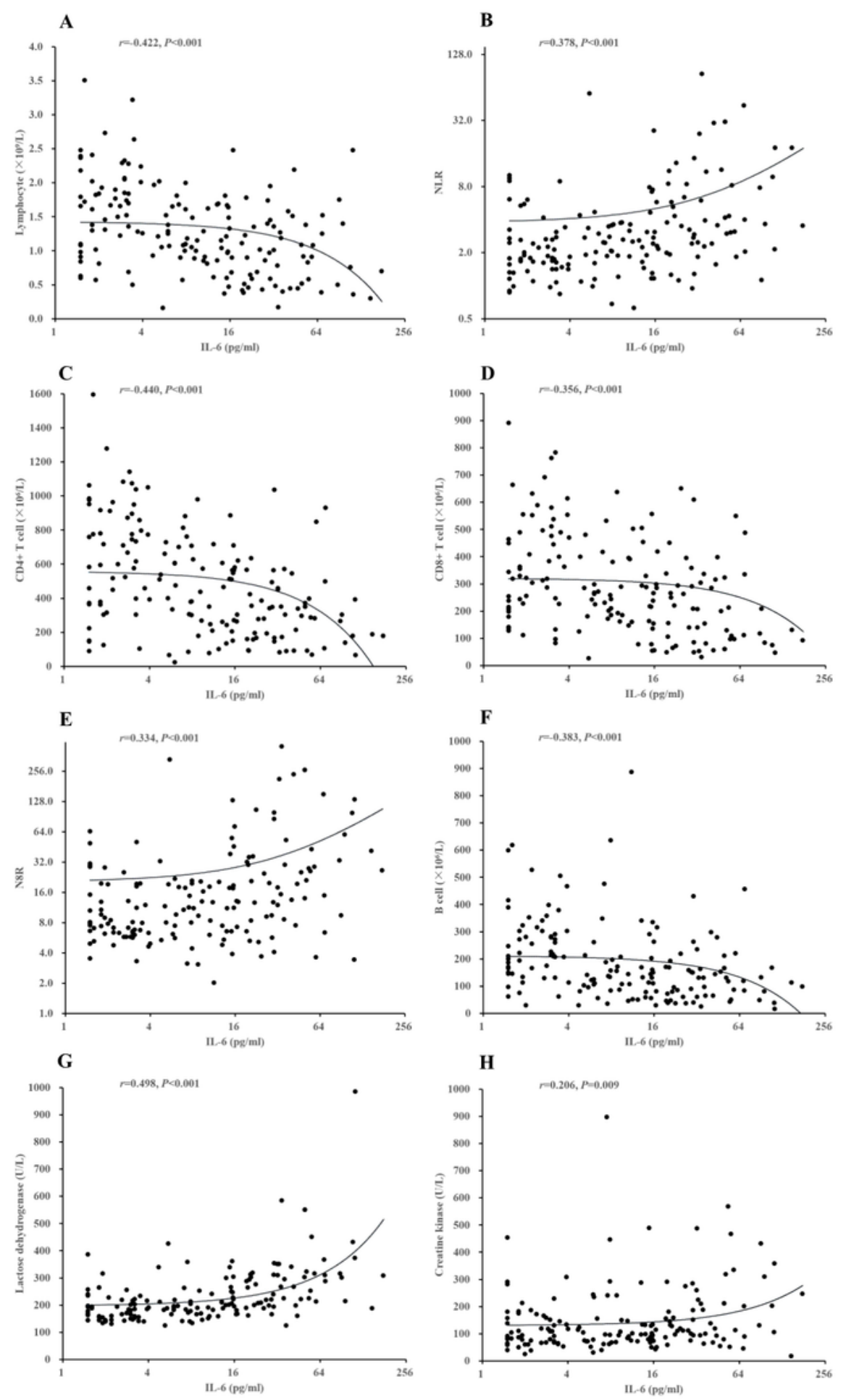

\section{Figure 1}

Correlations between IL-6 and lymphocyte count (A), NLR (B), CD4+ T cell count (C), CD8+ T cell count $(D), N 8 R(E), B$ cell count $(F)$, serum lactate dehydrogenase level $(G)$, and serum creatine kinase level $(H)$. NLR: neutrophil-to-lymphocyte ratio; N8R: neutrophil-to-CD8+ T cell ratio. 

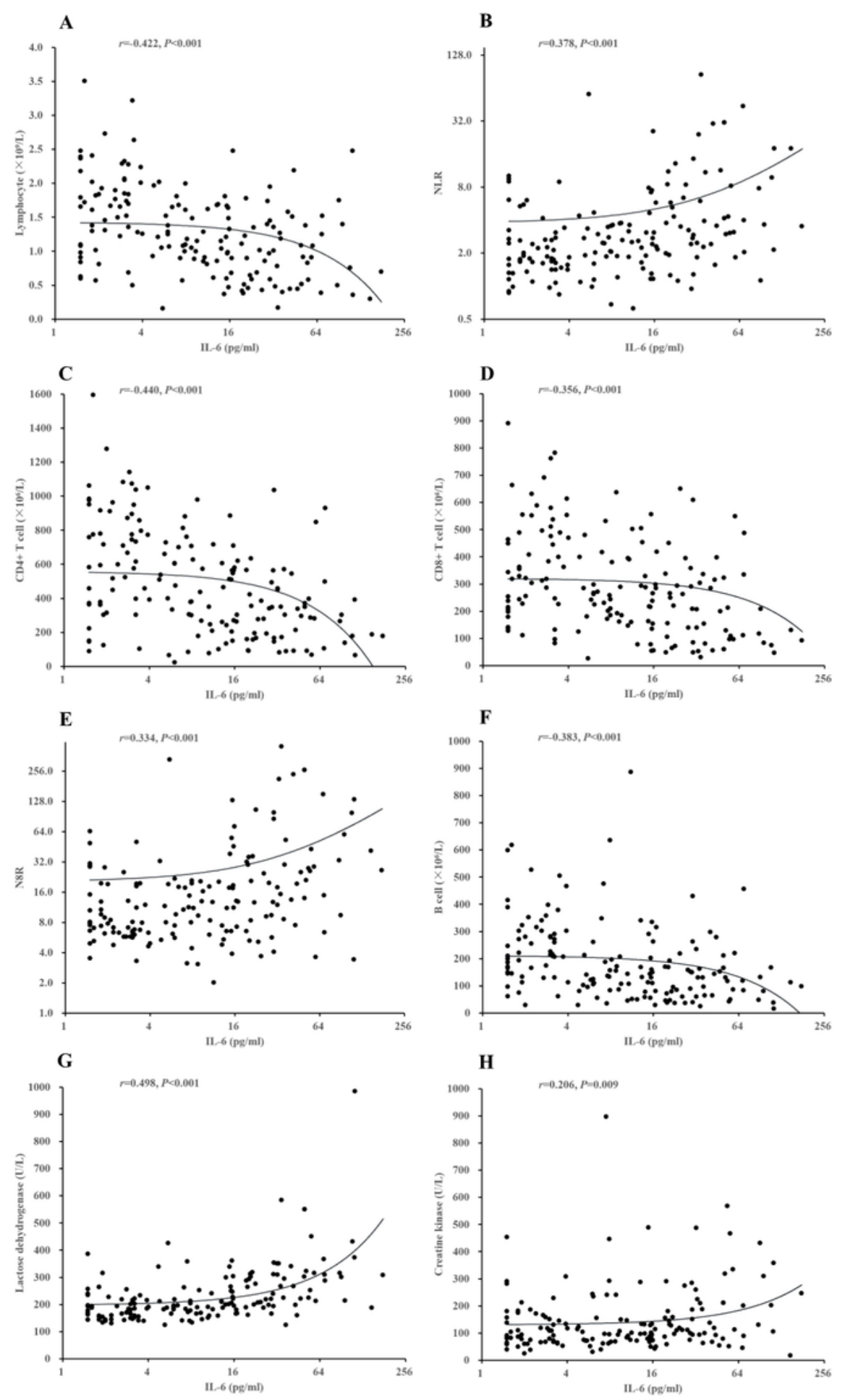

\section{Figure 1}

Correlations between IL-6 and lymphocyte count (A), NLR (B), CD4+ T cell count (C), CD8+ T cell count $(D), N 8 R(E), B$ cell count $(F)$, serum lactate dehydrogenase level $(G)$, and serum creatine kinase level $(H)$. NLR: neutrophil-to-lymphocyte ratio; N8R: neutrophil-to-CD8+ T cell ratio. 

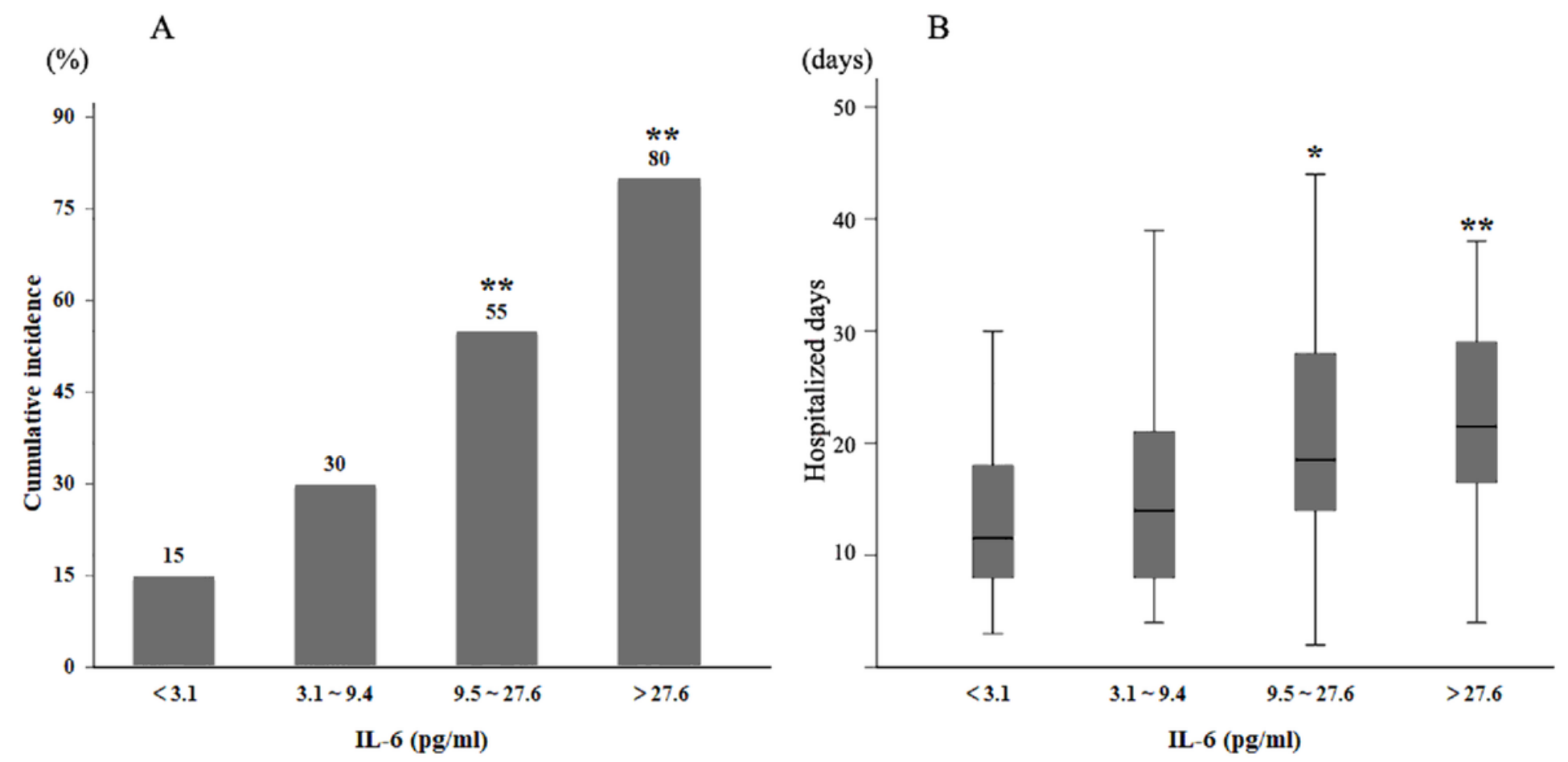

Figure 2

The cumulative incidence of severe COVID-19 (A) and mean duration of hospitalization (B) in patients grouped by IL-6 quartiles. ${ }^{*} p<0.01$ vs. first quartile; ${ }^{*} p<0.001$ vs. first quartile

A

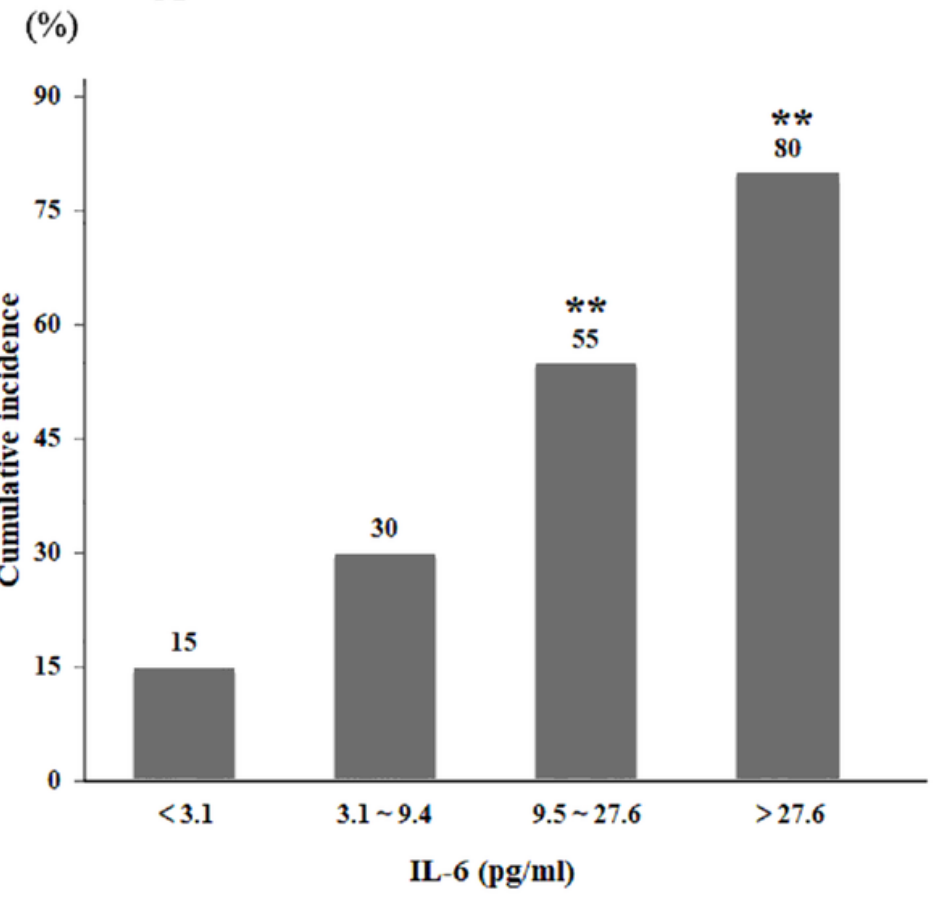

B

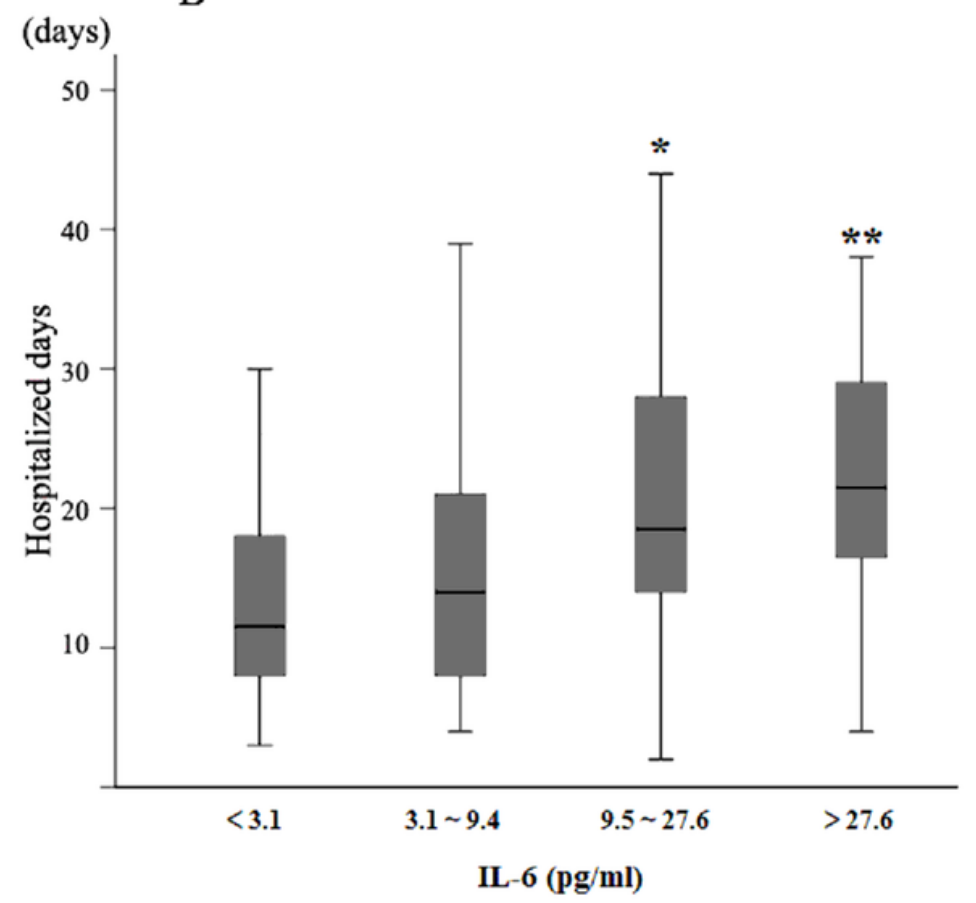

\section{Figure 2}

The cumulative incidence of severe COVID-19 (A) and mean duration of hospitalization (B) in patients grouped by IL-6 quartiles. ${ }^{*} p<0.01$ vs. first quartile; ${ }^{*} p<0.001$ vs. first quartile 